Bu makaleye atıfta bulunmak için/To cite this article:

BAYINDIR DURNA, N. DURNA, D. (2021). Dis Cürüklerinin Önlenmesinde Ebeveyn Tutumlarının Ceșitli Değişkenler Bakımından İncelenmesi. Atatürk Üniversitesi Sosyal Bilimler Enstitüsü Dergisi, 25 (Özel Sayı), 345-352.

\title{
Diş Çürüklerinin Önlenmesinde Ebeveyn Tutumlarının Çeşitli Değişkenler Bakımından İncelenmesi
}

\author{
Nurhan BAYINDIR DURNA (*) \\ Doğan DURNA ${ }^{(* *)}$
}

Öz: Toplumda diș çürüğü problemini kontrol altına alabilmek için öncelikle erken dönemde oral hijyen bilincinin ve eğitiminin yaygınlaştırlmasının, koruyucu hekimlik hizmetlerinin yeterli düzeyde sağlanmasının önemli olduğunu söyleyebiliriz. Diş çürüğü dağılımının belirlenmesinde 5, 12 ve 15 yaşları Dünya Sağlık Örgütü tarafindan kritik yaş grupları olarak değerlendirilmiştir. Bu yaştaki bireylerin ise çevreleri ve özellikle aileleri tarafindan yönlendirilmeleri, ağlz ve dişsağlı̆̆l konularında bilinçlendirilmeleri gerekmektedir. Bu bilinçlendirmenin, öncelikle ebeveynler tarafindan gerçekleştirilmesi arzu edilen bir husustur. Ebeveynlerin diş çürüklerinin önlenmesine dair bilgi düzeyleri, ağız ve diş sağllğına verdikleri önem, kendilerine ve çocuklarına ilişkin yaklaşımları, çocuklarının diş să̆lığına gösterdikleri özen ve diş̧̧ürüklerinin önlenmesindeki çabaları gibi aile tutumlarının; cinsiyet, sahip olunan çocuk sayısı, sosyoekonomik düzey, ailenin yaşadı̆̆ yer ve anne baba eğitim düzeyi değişkenleri bakımından incelenmesi bu araştırmanın amacını oluşturmaktadır. Bu çalışma tarama modelinde betimsel bir araştırmadır. Tarama modelleri, geçmişte ya da var olan bir durumu var olduğu şekliyle betimlemeyi amaçlayan modeldir. Çalışmanın verileri ise araştırmacı tarafindan geliştirilen ve araştırmanın amacına uygun olarak hazırlanan anket formunun 318 aileye uygulanmast ile toplanmıştır. Elde edilen veriler uygun istatistiki testler ile analiz edilerek araştırma sonuçları ortaya konulmuştur.

Anahtar Kelimeler: Diş çürükleri, diş çürüklerini önleme, ebeveyn tutumu, betimsel tarama

\section{Investigation of Parental Attitudes in Various Variables in Prevention of Tooth Cards}

Abstract: In order to control the problem of dental caries in the society, we can say that it is important to spread oral hygiene awareness and education in the early period and to provide preventive medicine services at an adequate level. 5, 12 and 15 years of age were considered as critical age groups by the World Health Organization in determining the distribution of dental caries. Individuals at this age need to be guided by their environment and especially by their families, and to raise awareness about oral and dental health. It is desirable that this awarenessraising be carried out primarily by the parents. Family attitudes such as the knowledge level of parents on the prevention of dental caries, the importance they attach to oral and dental health, their approach to themselves and their children, the care they show for their children's dental

\footnotetext{
${ }^{*}$ Dr. Öğr. Üyesi, Atatürk Üniversitesi Diş Hekimliği Fakültesi (e-posta: nurhanbayindir@atauni.edu.tr) (D) ORCID ID. https://orcid.org/0000-0003-2223-7984

${ }^{* *}$ Dr. Öğr. Üyesi, Atatürk Üniversitesi Diş Hekimliği Fakültesi (e-posta: dogandurna@atauni.edu.tr) (D) ORCID ID. https://orcid.org/0000-0001-5341-6024

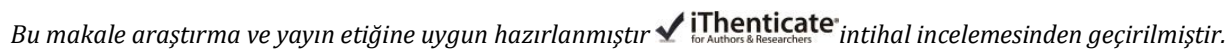


health and their efforts to prevent dental caries; The aim of this study is to examine the variables of gender, number of children, socioeconomic level, place of residence of the family and education level of the parents. This study is a descriptive research in scanning model. Scanning models are models that aim to describe a past or existing situation as it exists. The data of the study were collected by applying the questionnaire form, which was developed by the researcher and prepared in accordance with the purpose of the research, to 318 families. The data obtained were analyzed with appropriate statistical tests and the results of the research were revealed.

Keywords: Dental caries, prevention of dental caries, parental attitude, descriptive screening

Makale Gelis Tarihi: 20.09.2021

Makale Kabul Tarihi: 15.11.2021

DOI: 10.53487/ataunisosbil.953033

\section{Giriş}

Sağlık; psikoloji, beden, ruh ve kişinin sosyal durumu bakımından tam bir iyilik hâli olarak tanımlanır. Kişinin toplumsal hayatını sürdürmesinde ve yaşam kalitesini yükseltmesinde önemli bir husustur. Sağlığın geliştirilmesi toplumsal bilincin oluşturulması ile mümkündür. Ağız ve diş sağlığı açısından sağlıklı olabilmek ancak çocukluk döneminde başlayan sağlam bir bilinç, ağız bakımı ve periyodik hekim kontrolleri ile sağlanabilir. Bu yönüyle gerek ağız ve diş sağlı̆̆ ve gerekse vücut bütünlüğüne yönelik sağlığın korunması ailesel ve bireysel şuurun kazandırılması ile mümkün olacaktır.

Sağlığın teşviki ve geliştirilmesi araştırmaları, ağız sağlı̆̆ının zayıf olduğu bir toplumda genel sağlığın iyi olmasının imkânsız olduğunu göstermektedir. Sağlıklı bir ağzın çocukluk döneminde gerekli eğitimler ile elde edilebileceği düşünüldüğünde, belli bir süreçte kazanılan farkındalık göz önüne alındığında, ebeveyn ve çocuk ilişki bağlamında bu konunun çalışılması önemli olduğunu söyleyebiliriz. Çocukların bilgileri eğitimle ve ailelerinin desteği ve rehberliği ile gelişecektir. Geleceğin sağlıklı bir toplum için çok önemli olan bireysel bilincin ancak çocuklukta kazanılabileceği bilinmektedir (Akıncı, 2008). Diş çürüğü, diş yüzeyinde biriken, gıdalardaki şekerleri metabolize eden ve asit üreten ağız boşluğu florasından mikroorganizmaların etkisi altında dişlerin sert dokularında meydana gelen biyokimyasal bir değişikliklerdir. (Karabekiroğlu ve Ünlü, 2017). Diş çürüğü, ağızdaki bazı bakterilerin, belirli faktörler nedeniyle dişin sert yapısını yok etmesi durumudur. Bu faktörler diş çürüğünün oluşumu tetikler; ağızda karyojenik bakterilerin bulunması, bu bakterilerin beslenmesi için şeker gibi maddeler, beslenme sonucu oluşan enzimler veya bazı gıdaların tüketimi sırasında oluşan asitler ve bu asitlerin dişlere vereceği zarar seklinde geçen süre diş çürümesi olarak adlandırılır (Larsen et al., 1991; Pinkham et al., 2009). Diş çürüğü, yüksek gelire ya da orta düzeyde gelire sahip ülkelerde genel sağlığı etkileyen oldukça önemli bir halk sağlı̆̆ı sorunudur ve gelişmemiş ülkelerde daha yaygın bir sorun haline gelmektedir. (Kırzıoğlu, 2014). Dünya Sağlık Örgütü (WHO) tarafindan 2003 yllında yayınlanan Dünya Ağız Hijyeni Raporunda, ağız hastalıklarının önlenmesi ve ağız hijyeninin iyileştirilmesi için geliştirilen stratejiler üzerinde durmuştur (Peteren 2003; akt. Kırzıoğlu, 2014). 
Bebeklikten yaşlılığa kadar ağız ve diş sağlığı sorunlarının görülmesi durumu kaçınılmaz bir husus olmasına karşın, Dünya Sağlık Örgütü ağız sağlığı düzeyinin belirlenmesinde 5, 12, 15 yaş gruplarındaki bireylerin ağız sağlığı düzeyinin belirlenmesinin yeterli olduğunu dile getirmektedir (WHO, 2013)). Ağız ve diş sağlığının istenen düzeyde olmadığı bir toplumda, iyi bir genel sağlığa ulaşmanın imkânsız olduğu durumu sağlığı geliştirme çabalarının göstergeleri olarak ifade dilmektedir. Diş çürüğü, bu alanda ortaya onulan görüşlere göre önleyici tedbirlerle önlenebilen bir hastalık olarak görülmektedir (Pinkham et al., 2009). Sağlıklı bir ağza çocukluk döneminde verilen eğitim ve farkındalıkla ulaşılabileceği düşüncesiyle ailelere ve okullara birçok görev ve sorumluluk düşmektedir. Bu konu ile ilgili araştırmaların çok önemli olduğu düşünülmektedir. Çocukların bilgileri eğitimle, ailelerinin desteği ve rehberliği ile gelişecektir. Gelecekte sağlıklı bir toplum için çok önemli olan bireysel bilincin ancak çocuklukta kazanılabileceği bilinmektedir. (Akıncı, 2008). Bu bilinçlendirmenin gerçekleşmesinde çocuğun dünyaya geldiği ailenin sağlığa, dolayısıyla da diş sağlığına olan tutumu, çocukların sağlıklı bireyler olarak yetişmesinde önemli görülmektedir. Bu çalışma ile ağız ve diş sağlığının oluşumunda önemli görevler üstlenen aile kurumunun çocuklarının diş bakımlarına yönelik tutumları çeşitli değişkenler açısından incelenmiştir ve araştırmada şu sorulara cevap aranmıştır:

1. Diş çürüklerinin önlenmesinde ebeveyn tutumları cinsiyet değişkenine göre anlamlı düzeyde farklılaşıyor mu?

2. Diş çürüklerinin önlenmesinde ebeveyn tutumları çocuk sayısı değişkenine göre anlamlı düzeyde farklılaşıyor mu?

3. Diş çürüklerinin önlenmesinde ebeveyn tutumları gelir düzeyi değişkenine göre anlamlı düzeyde farklılaşıyor mu?

4. Diş çürüklerinin önlenmesinde ebeveyn tutumları yaşanılan yer değişkenine göre anlamlı düzeyde farklılaşıyor mu?

5. Diş çürüklerinin önlenmesinde ebeveyn tutumları eğitim düzeyi değişkenine göre anlamlı düzeyde farklılaşıyor mu?

\section{Araştırmanın Yöntemi}

Bu çalışma tarama modelinde betimsel bir araştırmadır. Tarama modelleri, geçmişte ya da var olan bir durumu var olduğu şekliyle betimlemeyi amaçlayan modeldir (Karasar, 2012). Bu çalışma ile ebeveynlerin çocuklarının diş sağlığına olan tutumlarının cinsiyet, çocuk sayısı, sosyoekonomik düzey, yaşanılan yer ve eğitim düzeylerine göre anlamlı olarak farklılaşıp farklılaşmadığının araştırılması amaçlanmıştır. Araştırmada veri toplama aracı olarak çocuk diş sağlığına yönelik ebeveyn tutumları anketi kullanılmıştır. Anket iki bölümden oluşmaktadır. Birinci bölüm, katılımcıların kişisel bilgilerine yönelik 7 sorudan; ikinci bölüm, ebeveynlerin çocuklarının diş sağlığına olan tutumlarına ilişkin görüşlerine yönelik 14 sorudan ve beşli likert tipi maddeden oluşmaktadır. Ebeveynlerin çocuklarının diş sağlığına yönelik tutumlarını belirlemek amacıyla hazırlanan anket için literatür taraması yapılarak 22 maddeden oluşan madde havuzu oluşturulmuştur. Uzman görüşleri alındıktan sonra 8 madde elenerek 14 maddeye düşürülmüştür. Anketin son hâli, çalışma grubu dışında 52 kişiye uygulanmış ve madde iç tutarlılığına ilişkin yapılan Cronbach Alpha güvenirlik katsayısı 0,92 bulunmuştur. 
İlgili anket 310 aileye çevrimiçi uygulanmış, eksik görülen uygulamalar çıkarılarak 276 ailenin cevapları SPSS ile analiz edilmiş ve araştırma sonuçlarına ulaşılmıştır.

\section{Bulgular}

Diş çürüklerinin önlenmesinde ebeveyn tutumlarında cinsiyete göre anlamlı farklılık olup olmadığını belirlemek için Bağımsız Örneklemler için t Testi yapılmış ve elde edilen bulgular Tablo 1'de sunulmuştur. Ayrıca Bağımsız Örneklemler için t Testi'nin önemli bir koşulu olan varyansların homojenliği için Levene testi yapılmış $\mathrm{F}=.225$, $\mathrm{p}>.05$, bu koşulun sağlandığı bulunmuştur.

Tablo 1. Cinsiyet Değişkenine Ilişskin t Testi Bulguları

\begin{tabular}{cllllll}
\hline & Cinsiyet & N & $\bar{X}$ & Ss & t & p \\
\hline $\begin{array}{c}\text { Ebeveyn } \\
\text { Tutumu }\end{array}$ & Erkek & 160 & 54.85 & 8.41 & 3.317 & .01 \\
& Kadın & 116 & 58.08 & 7.51 & & \\
\hline
\end{tabular}

Tablo 1 incelendiğinde diş çürüklerinin önlenmesinde ebeveyn tutumlarının cinsiyete göre anlamlı olarak farklılaşıp farklılaşmadığını belirlemek üzere Bağımsız Örneklemler İçin t Testi sonucunda $\mathrm{t} 282=3.317, \mathrm{p}<.05$ cinsiyete göre anlamı olarak farklılaşma olduğu bulunmuştur.

Diş çürüklerinin önlenmesinde ebeveyn tutumlarında çocuk sayısına göre anlamlı farklılık olup olmadığını belirlemek için ANOVA yapılması planlanmış ancak varyans homojenliği sağlanamadığı için nonparametrik karşıllğg olan Kruskall Wallis H testi yapılmış ve elde edilen bulgular Tablo 2'de sunulmuştur.

Tablo 2. Çocuk Sayısına İlişkin Kruskal Wallis H Bulguları

\begin{tabular}{ccccccc}
\hline & $\begin{array}{c}\text { Çocuk } \\
\text { Sayısı }\end{array}$ & N & $\begin{array}{c}\text { Sira } \\
\text { Ort. }\end{array}$ & sd & $\mathbf{x}^{2}$ & P \\
\hline $\begin{array}{c}\text { Ebeveyn } \\
\text { Tutumları }\end{array}$ & 1 & 71 & 151.63 & & & \\
& 2 & 112 & 138.83 & & & \\
& 3 & 59 & 127.22 & & & \\
& 4 & 22 & 133.70 & & & \\
& 5 & 10 & 118.55 & & \\
\hline
\end{tabular}


Tablo 2 incelendiğinde diş çürüklerinin önlenmesinde ebeveyn tutumlarının çocuk sayısına göre anlamlı olarak farklılaşıp farklılaşmadığını belirlemek üzere yapılan Kruskal Wallis H testi sonucunda ebeveyn tutumlarında çocuk sayısına göre $x^{2}=3.815$, $\mathrm{sd}=4, \mathrm{p}<.05$ anlamlı farklılaşma olduğu bulunmuştur. Çocuk sayısı arttıkça diş çürüklerinin önlenmesinde ebeveyn tutumlarının azaldığı görülmüştür.

Diş çürüklerinin önlenmesinde ebeveyn tutumlarında ailenin gelir düzeyine göre anlamlı farklılık olup olmadığını belirlemek için ANOVA yapılması planlanmış ancak varyans homojenliği sağlanamadığ için nonparametrik karşılığı olan Kruskall Wallis H testi yapılmış ve elde edilen bulgular Tablo 3 'te sunulmuştur.

Tablo 3. Gelir Düzeyine İlişkin Kruskal Wallis H Bulguları

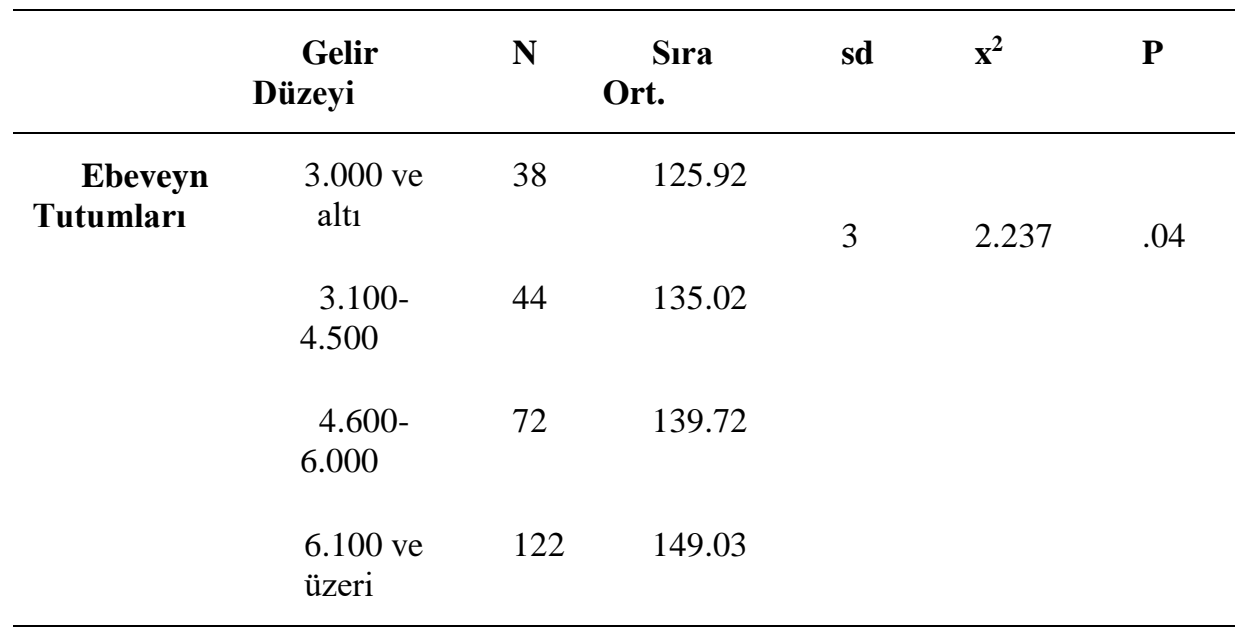

Tablo 3 incelendiğinde diş çürüklerinin önlenmesinde ebeveyn tutumlarının ailenin gelir düzeyine göre anlamlı olarak farklılaşıp farklılaşmadığını belirlemek üzere yapılan Kruskal Wallis $\mathrm{H}$ testi sonucunda ebeveyn tutumlarında gelir düzeyine göre anlamlı farklılaşma olduğu bulunmuştur $\left(\mathrm{x}^{2}=2.237, \mathrm{sd}=3, \mathrm{p}<.05\right)$. Dolayısıyla gelir düzeyi arttıkça ebeveynlerin çocuklarına yönelik diş bakımlarındaki hassasiyetlerinin de arttığını söyleyebiliriz.

Diş çürüklerinin önlenmesinde ebeveyn tutumlarında yaşanılan yere göre anlamlı farklılık olup olmadığını belirlemek için Bağımsız Örneklemler için t Testi yapılmış ve elde edilen bulgular Tablo 4'te sunulmuştur. Ayrıca Bağımsız Örneklemler için t Testi'nin önemli bir koşulu olan varyansların homojenliği için Levene testi yapılmış $\mathrm{F}=2.089, \mathrm{p}>.05$, bu koşulun sağlandığı bulunmuştur. 
Tablo 4. Yaşanılan Yer Değişkenine İlişkin t Testi Bulguları

\begin{tabular}{cllllll}
\hline & Değişken & $\mathbf{N}$ & $\bar{X}$ & Ss & t & p \\
\hline $\begin{array}{c}\text { Ebeveyn } \\
\text { Tutumu }\end{array}$ & Köy/İlçe & 70 & 56.37 & 11.25 & 8.760 & .03 \\
& İl & 206 & 67.51 & 8.48 & & \\
\hline
\end{tabular}

Tablo 4 incelendiğinde diş çürüklerinin önlenmesinde ebeveyn tutumlarının yaşanılan yere göre anlamlı olarak farklılaşıp farklılaşmadığını belirlemek üzere Bağımsız Örneklemler İçin t Testi sonucunda yaşanılan yere göre ebeveyn tutumlarında anlamı farklılaşma olduğu bulunmuştur $\left(\mathrm{t}_{283}=8.760, \mathrm{p}<.05\right)$. Buna göre kırsal kesimde yaşayan bireylerin çocuklarını diş tedavisine yönlendirme noktasında daha yetersiz kaldıkları düşünülebilir.

Diş çürüklerinin önlenmesinde ebeveyn tutumlarında eğitim düzeyine göre anlamlı farklılık olup olmadığını belirlemek için ANOVA yapılması planlanmış ancak varyans homojenliğgi sağlanamadığı için nonparametrik karşıllğg olan Kruskall Wallis H testi yapılmış ve elde edilen bulgular Tablo 5'te sunulmuştur.

Tablo 5. Eğitim Düzeyine İlişkin Kruskal Wallis H Bulguları

\begin{tabular}{ccccccc}
\hline & Değişken & N & $\begin{array}{c}\text { Sira } \\
\text { Ort. }\end{array}$ & sd & $\mathbf{x}^{2}$ & P \\
\hline $\begin{array}{c}\text { Ebeveyn } \\
\text { Tutumları }\end{array}$ & Lise ve altı & 68 & 132.85 & & & \\
& Üniversite & 130 & 150.38 & 3 & 8.678 & .03 \\
& $\begin{array}{c}\text { Yüksek } \\
\text { Lisans }\end{array}$ & 33 & 152.59 & & & \\
& Doktora & 45 & 153.19 & & & \\
\hline
\end{tabular}

Tablo 5 incelendiğinde diş çürüklerinin önlenmesinde ebeveyn tutumlarının yaşanılan eğitim düzeylerine göre anlamlı olarak farklılaştığı ve bu farkın Lise ve altı düzeyde eğitim düzeyine sahip olanların aleyhine olduğu belirlenmiştir. Bu kapsamda lise ve altı düzeyde eğitim düzeyine sahip olan ebeveynlerin tutumlarının üniversite ve üstü eğitim düzeyine sahip olanlara göre daha olumsuz olduğu düşünülebilir. 


\section{Sonuç ve Tartışma}

Araştırmadan elde edilen bulgular değerlendirildiğinde çocukların diş sağlı̆̆ına yönelik ebeveyn tutumlarının cinsiyet değişkenine göre anlamlı düzeyde farklılaştı̆̆ı ve kadınların, çocuklarının diş bakımlarına yönelik olumlu tutumlarının erkeklere göre daha yüksek olduğu görülmüştür. Çocukların genel olarak anneleri ile geçirdikleri vaktin daha fazla olması durumu annelerin tutumlarının yüksek olmasında etkili bir unsur olabileceğini söyleyebiliriz. Ebeveynlerin çocuk sayılarının diş bakımına yönelik tutumu farklılaştırdığını ve çocuk sayısı arttıkça diş çürüklerinin önlenmesinde ebeveyn tutumlarının azaldığını araştırma bulgularına göre söyleyebiliriz. Bilgili (2009) yapmış olduğu araştırmasında, ailelerin çocuk sayısı arttıkça diş çürük oranının da arttığını dile getirmiştir. Bu sonuç, ailenin sahip olduğu çocuk sayısının artmasının diş çürüklerinin önlenmesindeki tutumlarını olumsuz etkileyen bir durum olduğu sonucunu desteklemektedir. Ebeveynlerin sosyoekonomik düzeylerinin çocuklarının diş sağlığına yönelik tutumlarını anlamlı düzeyde farklılaştırdığı görülmüşsür. Ailelerin gelir düzeyi arttıkça çocuk diş sağlığına yönelik tutumlarının da olumlu düzeyde arttığı sonucuna ulaşılmıştır. Bilgili (2009)'un çalışmasında, "sosyoekonomik düzeyi yüksek ailelerin çocuklarının ağız-diş sağlığı durumunun daha iyi olduğu, diş hekimine gitme sıklığının da daha fazla olduğu" sonucu, ailelerin sosyoekonomik düzeyleri ile diş bakımına yönelik tutumlarına ilişkin araştırma sonucumuzu desteklemektedir. Benzer olarak Tokuç ve Yıldırım (2021)'in çalışmalarında ailenin gelir düzeyinin artması ile çocuğun ağız ve diş sağlığı alışkanlıklarının geliştiği ve tedavi hizmetlerine ulaşımın kolaylaştı̆̆ sonucu da araştırma sonuçlarımızı desteklemektedir. Ebeveynlerin yaşadıkları yer değişkenin ise çocuklarının diş sağlığına yönelik tutumlarını anlamlı düzeyde farklılaştırdığ görülmüştür. Köy ve ilçe merkezlerinde yaşayan ebeveynlerin şehir merkezinde yaşayanlara göre çocuklarının diş sağlığına daha az önem verdikleri sonucuna ulaşılmıştır. Ailenin yaşadığı yer değişkeninin çocuklarının diş sağlığına yönelik tutumu etkilemesindeki önemli faktörün sağlık hizmetlerine ulaşımın kolaylığı ile ilgili olduğunu söyleyebiliriz. Araştırma bulgularına göre ebeveynlerin eğitim düzeylerinin de çocuklarının diş sağlı̆̆ına yönelik tutumlarını anlamlı düzeyde farklılaştırdığı görülmüştür. Ailenin eğitim düzeyi arttıkça çocuk diş sağlığına yönelik tutumlarının olumlu düzeyde arttığı sonucuna ulaşılmıştır. Bilgili (2009)'un eğitim düzeyi düşük ailelerde diş çürüğü oranının yüksek, eğitim düzeyi yüksek ailelerde ise diş çürük oranının düşük olduğu sonucu, araştırma sonuçlarımızı destekler niteliktedir.

\section{Öneriler}

1. Özellikle düşük gelir düzeyindeki aileler ile köy ve kırsal kesimde yaşayan ailelerin çocuk diş sağlığı hakkında bilinçlendirilmesi,

2. Çocuk diş sağlığına yönelik farkındalık oluşturacak eğitim çalışmaları yapilmasi,

3. Koruyucu diş hekimliği hizmetlerine ulaşılabilirliğin kolaylaştırılması araştırma sonuçlarından hareketle önerilmektedir. 


\section{Kaynaklar}

Akıncı Z. (2008). Karma Dişlenme Dönemindeki Öğrencilerin AğıZ- Diş Sağlı̆̆ı Durumunun ve Bu Konudaki Eğitim Gereksinimlerinin Belirlenmesi. Yüksek lisans tezi. Ankara.

Bilgili (2009). Kliniğimize Başvuran Çocuklar ile Ebeveynlerinin Diş Sağlı̆̆ının Değerlendirilmesi ve Sosyodemografik Faktörlerle İlişkisinin Araştırılması. Yüksek Lisans Tezi. İstanbul.

Karabekiroğlu, S ve Ünlü, N. (2017). Toplum Bazlı Koruyucu Ağız Diş Sağlı̆̆ı Programlarında Erken Dönem Koruyucu Uygulamaların Yeri ve Önemi. EÜ Dişhek Fak. Dergisi, 38(2), 89-100.

Karasar, N. (2012). Bilimsel araştırma yöntemi. Nobel Yayıncılık.

Larsen C. S. et al. (1991) "Dental Caries Evidence for Dietary Change: An Archeological Context", Advances in Dental Anthropology, M. A. Kelley and C. S. Larsen (Eds.) Wiley-Liss, 179-202.

Pinkham J. R. , Casamassimo P. S. , Fields H. W. , McTigue D. J. ve Nowak A. J. (2009) Çocuk Diş Hekimliği: Bebeklikten Ergenliğe (4. Basım), (T. Tortop ve Ö. Tulunoğlu, Çev.) Atlas Kitapçılık.

World Health Organization (2013). Oral health surveys basic methods 5th edition.

Kırzıoğlu, Z. (2014). Diş Çürüklerini Önlemede Kullanılan Alternatif Materyaller. Atatürk Üniversitesi Diş Hekimliği Fakültesi Dergisi, 9, 104-112.

Petersen PE. The World Oral Health Report 2003: continuous improvement of oral health in the 21st century - the approach of the WHO Global Oral Health Programme. Community Dent Oral Epidemiol 2003, 31, 3-24.

Tokuç, M. ve Yıldırım S. (2021). Ailelerin Çocuklarının Ağız ve Diş Sağlığı Konusundaki Tutum ve Davranışlarının Değerlendirilmesi. Türkiye Klinikleri Diş Hekimliği Bilimleri Dergisi. 27(3), 381-92. 